\title{
Evaluation of Amitraz and Diazinon against Rhipicephalus decoloratus and Amblyomma variegatum in Bako Agricultural Research Center
} Temesgen Tesfaye ${ }^{1}$, Chala Mohammed ${ }^{1 *}$, Lama Yimer ${ }^{1}$, Misgana Duguma ${ }^{1}$ and Mammo Mokonnen ${ }^{2}$

${ }^{1}$ School of Veterinary Medicine, Wollega University, Nekemte, Ethiopia

${ }^{2}$ Bako Agricultural Research Center, Ethiopia

\begin{abstract}
Ticks are blood feeding ectoparasites that induce huge production losses in livestock industry and creating serious public health problems in the world. Although the use of chemicals is still the most effective method of tick control, uncontrolled applications may have accelerated the emergence of tick resistance to several active ingredients available. This study was conducted to assess the efficacy of commonly used acaricides (amitraz and diazinon) against Rhipicephalus decoloratus and Amblyomma variegatum collected from cattle by using Adult immersion test method. The in-vitro test employed an adult immersion technique. For laboratory experiment, adult ticks collected were exposed to Amitraz or Diazinon. The in-vitro assay showed no statistically significant tickicidal difference $(p>0.05)$ between these compounds, although amitraz proved a relatively better efficacy. For both acaricides, doubled concentration was more effective in tick killing. In conclusion, comparing the efficacy of the two acaricides, amitraz is the preferable one. Furthermore, right application and choice of acaricides, avoidance of uncontrolled utilization of commercial insecticides and Strategies involving the early detection of resistance needs to be pursued in order to avoid any resistance against ticks in cattle.
\end{abstract}

Keywords: Amblyomma varigaieum; Rhipicephalus decoloratus ticks; Amitraz; Diazinon; Efficacy; In-vitro testing; Cattle

\section{Introduction}

A wide range of internal and external parasitic diseases are found in domestic animals. Among external parasites, ticks are undoubtedly the most economically important ectoparasites of livestock on global scale [1]. The economic benefits of resolving questions about the epidemiology and control of tick-borne diseases in the vast cattleproducing areas of eastern and southern Africa, Latin America, Australia and the southern US motivated research by national and colonial governments in the affected countries plus efforts by international animal health companies to create and market products that provided a means for protecting cattle [2].

The infestation with ticks can cause vast losses in farm animal's production, due to tick borne diseases, tick paralysis and physical damage as well as to huge financial losses due to tick control [3]. The economic losses caused by the Rhipicephalus microplus tick are due to a reduction in meat and milk production, as well as a devaluation of leather due to skin lesions caused by high infestations and the possible installation of myiasis. This tick species is responsible for the transmission of Babesiosis (Babesia bovis and B. bigemina) and Anaplasmosis (Anaplasma marginale), hemoparasites that characterize the disease named Bovine Babesiosis and Anaplasmosis Complex. This tick also causes indirect economic harm due to the additional hours of work required, additional facility costs, acaricide acquisition and equipment used for its application [4].

The application of chemicals is still the most effective method of ticks' control. However, uncontrolled applications of commercial acaricides may have accelerated the emergence of tick resistance to several active ingredients available. Since acaricide introduction in Africa around 1890 , tick treatment relying on different application methods have been the main method of tick control in Africa, leading to numerous problems; environmental pollution, development of resistant tick strains and escalating costs [5]. Likewise, in Ethiopia, over the past decade's ticks are mainly controlled by using variety of acaricides; including organochlorines, organophosphates, carbamates, amidines or synthetic pyrethroids. However, with the most widespread, under or over concentration and frequent use of organochlorines and organophosphates compounds; ticks are likely to develop resistance in many countries and in Ethiopia [6].

Repeated use of acaricides besides being the environmental hazard, it is exposed to be resisted by tick species through time, and this forces frequent application at high concentrations which is more critical to the environment. Tick acaricide resistance is reported in various parts of the countries where tick and tick borne diseases are of major problem. Since tick infestation is one of the major reported problems in the area, repeated use of acaricides is the only option in high tick seasons [6].

The most common method to control ticks is use of different types of chemical acaricides which are used in different method of applications such as dressing, spraying, systemic and dipping. The prolonged incorrect use of acaricides may cause resistance in ticks against acaricides. The resistance can be caused by numbers of mechanisms [7], and when resistant ticks survive, they pass this ability by genetic to their offspring, the higher reproductive rate of ticks that have heritable resistance factors well resulting to increase in proportion of population of tick that carry genes of acaricides resistance [8].

Ticks are of importance to veterinary medicine because they can be an annoyance, cause harm due to their blood feeding and they

*Corresponding author: Chala Mohammed, School of Veterinary Medicine Wollega University, PO Box 395, Nekemte, Ethiopia, Tel: +251913115805; E-mail: chalamohammed@wollegauniversity.edu.et

Received July 06, 2016; Accepted October 03, 2016; Published October 07, 2016

Citation: Tesfaye T, Mohammed C, Yimer L, Duguma M, Mokonnen M (2016) Evaluation of Amitraz and Diazinon against Rhipicephalus decoloratus and Amblyomma variegatum in Bako Agricultural Research Center. J Vet Sci Technol 7: 389. doi: 10.4172/2157-7579.1000389

Copyright: @ 2016 Tesfaye T, et al. This is an open-access article distributed under the terms of the Creative Commons Attribution License, which permits unrestricted use, distribution, and reproduction in any medium, provided the original author and source are credited. 
Citation: Tesfaye T, Mohammed C, Yimer L, Duguma M, Mokonnen M (2016) Evaluation of Amitraz and Diazinon against Rhipicephalus decoloratus and Amblyomma variegatum in Bako Agricultural Research Center. J Vet Sci Technol 7: 389. doi: 10.4172/2157-7579.1000389

Page 2 of 5

can transmit many pathologic organisms. Tick infestation and tick borne disease control is based mainly on the use of acaricides. Thus, the most widely used method for effective control of ticks is the direct application of acaricides to host animals. Tick acaricide resistance is reported in various parts of the countries where tick and tick borne diseases are of major problem. Since tick infestation and resistance to acaricides were one of the major problems in the area, repeated use of acaricides and inadequate application throughout an extended period may promote population selection of acaricide resistant of ticks in high tick seasons and increasing the resistance problem.

Therefore, the main Objective of this study was: To assess the efficacy of most frequently used acaricides for the control of ticks at Bako Agricultural Research Centre, Oromia Regional State, Ethiopia.

\section{Materials and Methods}

\section{Description of study area}

The study was conducted at Bako Agricultural Research Center from November 2015 to March 2016. It is situated at $258 \mathrm{Km}$ west of Addis Ababa, in Gobu Sayo District, East Wollega Zone of Oromia regional state, Western Ethiopia and some $4 \mathrm{~km}$ away from the main high way that gains Addis Ababa to Nekemte. It is located at Latitude of $09006^{\prime} \mathrm{N}$ and Longitude of $37009^{\prime} \mathrm{E}$, and an Altitude of 1650 meters above sea level. The district has an average rain fall of $886.5 \mathrm{~mm}$ and an average temperature of $21.2^{\circ} \mathrm{C}$. The area was generally concluded as "Woina Dega" even though some of it was kola. The main rainfall season was from May to September, dry season being from December to April and their humidity was $57.83 \%$ [9]

The total area of the Bako Tibe District is about 64,469 hectares of land with animal population of 141,393 Cattle, 12,880 Sheep, 14,641 Goats, 3,795 Horses, 8,668 Donkeys, 1,054 Mules, 97,709 Poultry, 5,237 Feline and 4,894 Canine [10]. The vegetation type of the area is characterized by common savannah vegetation's like mango tree, stetrespermum kunthiamum (botoro), Dokma (locally), pilio stigma thonningii (wanza) acashia absinica(grar), Carissa idylis (agamsa) and others. The area is reach with wild game animals in main river systems and in savannah. Some of these wild animals are Apes, pigs, antelopes, Columbus monkey, baboons and others. According to the settlers and people, there are bushbucks, hyenas and others [9].

\section{Study population}

The study was conducted on different cattle breeds of Dairy Farm at Bako Agricultural Research Centre. It was carried out by collecting ticks from the animals for in-vitro efficacy evaluation of Amitraz $12.5 \%$ and Diazinon $60 \%$ EC. None of the cattle received acaricidal treatment one month before the start of tick collection for the experiments.

\section{Tick collection}

The Farm was selected on the history basis of complaints on acaricides failure. From the Farm, the engorged adult of Rhipicephalus decoloratus and Amblyomma variegatum were collected for in-vitro efficacy evaluation of Amitraz 12.5\% and Diazinon 60\% EC. At each collecting site, the entire body surfaces of the animals were examined thoroughly and adult ticks were collected from neck/dewlap, udder, perineum/anus and legs/belly in combination from the sampled cattle. The bottles were labeled by considering the predilection sites and sampled animals. All collected ticks were examined under stereomicroscope and identified to the Genus/species level using the taxonomic key described by [11].

\section{Study methodology and procedures}

For laboratory experiment, the engorged adult ticks were collected from Dairy Farm at Bako Agricultural Research Centre. The in vitro acaricidal efficacy study was conducted on two dominant tick species infesting Cattle in the area. Accordingly, Ambylomma variegatum and Rhipicephalus (R.) decoloratus were collected and exposed to Diazinon and Amitraz according to Holdsworth et al. [12] immersion technique.

The recommended (1:1000 for diazinon, 1:625 for amitraz), double (2:1000 for diazinon, 2:625 for amitraz) and half doses were prepared. $1 \mathrm{ml}$ of each liquor was added on Petri dish with a filter paper fit at its bottom. Then, the acaricide was evenly distributed and 10 ticks of equal size were placed on each Petri dish and it was closed. This was done separately for each species of tick. Distilled water was used as a control. The number of ticks alive or dead was counted after 24 hours of exposure. The experiment was repeated three times for precision and mean value was taken for the analysis.

\section{Data analysis}

The Collected data were recorded, organized, edited and analyzed using statistical package for social sciences (SPSS) Version 20. The results generated from the investigation were expressed using descriptive statistics (mean \pm standard error of mean, percentage and graphs).

\section{Results}

The present study revealed that a number of ticks died after exposure with acaricides in laboratory at recommended, half and double doses. There was no significant difference ( $p>0.05)$ between two acaricides on the killing effect at any of the three different concentrations tested against both species of ticks (Table 1). Although not statistically significant, amitraz seemed to be superior to diazinon as measured by antiparasitic efficacy (\%) estimation against both Amblyomma variegatum and $R$. decoloratus. However, both compounds appeared to have a comparable and relatively better efficacy ( $>90 \%$ at recommended dose) against both Amblyomma variegatum and $R$. decoloratus. Both compounds produced maximum efficacy only at their double recommended dose. The mean number of ticks died after distilled water exposure was not more than one (Figures 1 and 2). For the in vitro experiments, antiparasitic efficacy (AE) of each treatment was calculated using the following equation [13]:

\section{$\mathrm{AE}=[\mathrm{B}-\mathrm{T} / \mathrm{B}] / \mathrm{B}$}

Where AE is the antiparasitic efficacy, B is the mean number of surviving ticks in the control, and $\mathrm{T}$ is the mean number of surviving ticks in treatment (Table 1).

The sensitivity of Amblyomma variegatum to acaricides was compared based up on the result obtained. Even though, Amblyomma variegatum is sensitive to both acaricides at different concentration, it is relatively more sensitive to Amitraz as shown in Figure 1 above.

The study indicated that the sensitivity of. $R$. decoloratus to both acaricides was compared based up on the result obtained. $R$. decoloratus is moderately resistant to Diazinon when compared with amitraz as shown in Figure 2 above.

\section{Discussion}

The present study revealed that a number of ticks died after exposure with acaricides in laboratory at recommended, half and double doses. Even though, there was no significant difference $(p>0.05)$ 
Citation: Tesfaye T, Mohammed C, Yimer L, Duguma M, Mokonnen M (2016) Evaluation of Amitraz and Diazinon against Rhipicephalus decoloratus and Amblyomma variegatum in Bako Agricultural Research Center. J Vet Sci Technol 7: 389. doi: 10.4172/2157-7579.1000389

Page 3 of 5

\begin{tabular}{|c|c|c|c|c|c|}
\hline Treated tick & Treatment & NE & MNS & MND & AE (\%) \\
\hline & Amitraz RD & 10 & $1.33 \pm 0.577$ & $8.67 \pm 0.577$ & 98.52 \\
\hline & Amitraz HRD & 10 & $4.00 \pm 1.000$ & $6.00 \pm 1.000$ & 95.56 \\
\hline & Amitraz DRD & 10 & $0.67 \pm 0.577$ & $9.33 \pm 0.577$ & 99.25 \\
\hline \multirow[t]{7}{*}{ Amblyomma variegatum } & Diazinon RD & 10 & $3.00 \pm 1.000$ & $7.00 \pm 1.000$ & 96.67 \\
\hline & Diazinon HRD & 10 & $5.00 \pm 1.000$ & $5.00 \pm 1.000$ & 94.45 \\
\hline & Diazinon DRD & 10 & $3.33 \pm 0.577$ & $6.67 \pm 0.577$ & 96.31 \\
\hline & Distilled Water & 10 & $9.50 \pm 0.548$ & $0.50 \pm 0.548$ & 0 \\
\hline & Amitraz RD & 10 & $3.00 \pm 1.000$ & $7.00 \pm 1.000$ & 96.89 \\
\hline & Amitraz HRD & 10 & $5.00 \pm 1.000$ & $5.00 \pm 1.000$ & 94.82 \\
\hline & Amitraz DRD & 10 & $1.67 \pm 0.577$ & $8.33 \pm 0.577$ & 98.27 \\
\hline \multirow[t]{4}{*}{ R. decoloratus } & Diazinon RD & 10 & $5.00 \pm 1.000$ & $5.00 \pm 1.000$ & 94.82 \\
\hline & Diazinon HRD & 10 & $6.00 \pm 1.000$ & $4.00 \pm 1.000$ & 93.79 \\
\hline & Diazinon DRD & 10 & $3.33 \pm 0.577$ & $6.67 \pm 0.577$ & 96.55 \\
\hline & Distilled Water & 10 & $9.83 \pm 0.408$ & $0.17 \pm 0.408$ & 0 \\
\hline
\end{tabular}

Values are mean $\pm \mathrm{SD} ; \mathrm{RD}=$ Recommended Dose; DRD=Double Recommended Dose; HRD=Half Recommended Dose; NE=Number of Ticks Exposed; MNS=Mean Number of Ticks Survived; MND=Mean Number of Ticks Died; AE=Antiparasitic Efficacy

Table 1: In vitro ticks killing effect of Diazinon and Amitraz at recommended, Half and double doses of 24 hours post exposure of Amblyomma variegatum and $\mathrm{R}$. decoloratus.

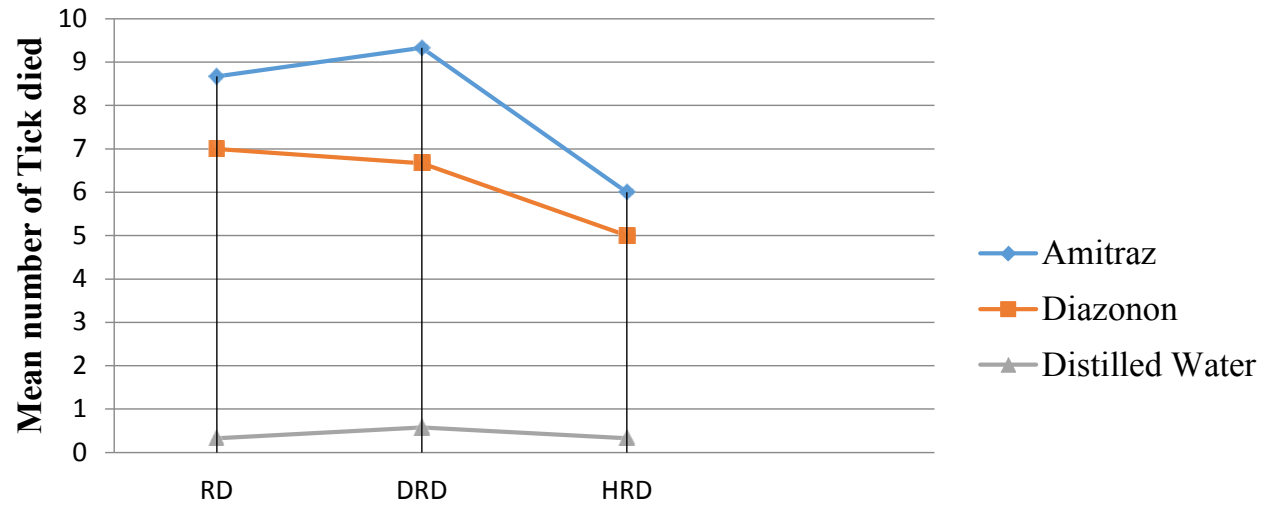

Different Concentrations of ectoparasiticides to which Amblyomma variegatum was exposed

Figure 1: Relative comparison of in vitro killing effect of amitraz and diazinon at recommended, double and half concentrations against Amblyomma variegatum $\mathrm{RD}=$ Recommended Dose; $\mathrm{DRD}=$ Double Recommended Dose; HRD=Half Recommended Dose.

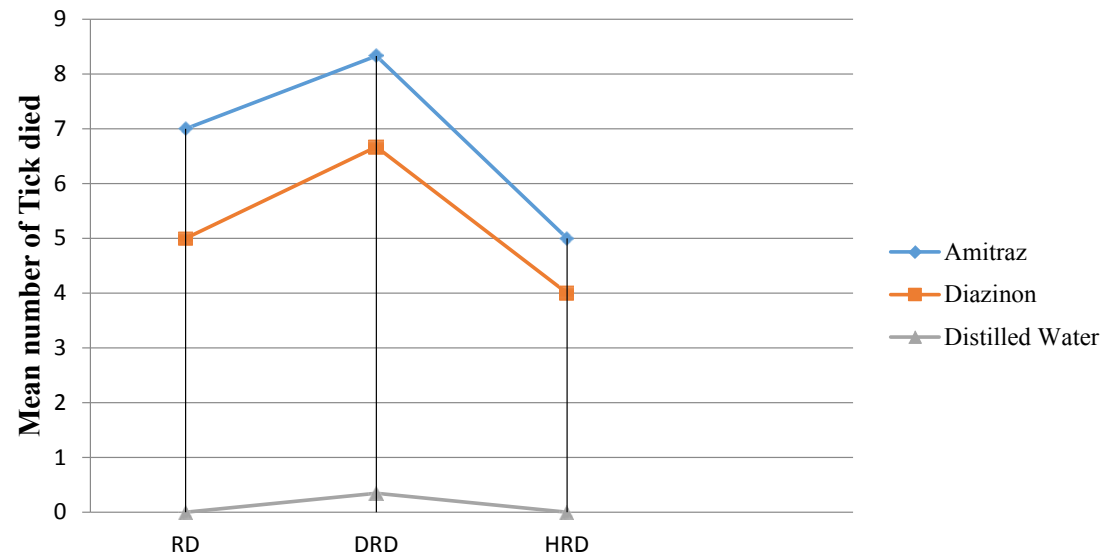

Different Concentrations of ectoparasiticides to which Rhipicephalus

decoloratus was exposed

Figure 2: Relative comparison of in vitro killing effect of amitraz and diazinon at double, recommended and half concentrations against $R$. decoloratus. $\mathrm{RD}=$ Recommended Dose; $\mathrm{DRD}=$ Double Recommended Dose; HRD=Half Recommended Dose. 
Citation: Tesfaye T, Mohammed C, Yimer L, Duguma M, Mokonnen M (2016) Evaluation of Amitraz and Diazinon against Rhipicephalus decoloratus and Amblyomma variegatum in Bako Agricultural Research Center. J Vet Sci Technol 7: 389. doi: 10.4172/2157-7579.1000389

Page 4 of 5

between two acaricides on the killing effect at any of the three different concentrations tested against both species of ticks, amitraz seemed to be effective than diazinon as measured by antiparasitic efficacy estimation against both Amblyomma variegatum and $R$. decoloratus. However, both compounds appeared to have a comparable and relatively better efficacy ( $>90 \%$ at recommended dose) against both Amblyomma variegatum and $R$. decoloratus and produced maximum efficacy only at their double recommended dose.

The present result showed that Amitraz (98.52) is more effective than Diazinon (96.67) at a recommended dose to Amblyomma variegatum. Present study agrees with Eshetu et al. [14] who reported that Amitraz at recommended concentration provides better efficient oviposition inhibition than Diazinon on Amblyomma and other ticks. However, the present study disagrees with the report of Furlong et al. [15] who found mean efficacy of $47.9 \%$ for amitraz, Santana [16] who reported a low efficacy of amitraz 40.5\%, Campos and Oliveira [17] of $30.95 \%$ and Camillo et al. [18] also observed low efficacy of Amitraz in some tick populations, in Northeast region of Brazil. This difference might be associated with the method of application of acaricides.

The present finding shows that, Amitraz is the most preferable than Diazinon to control $R$. decoloratus ticks with the antiparasitic efficacy of $96.89 \%$ whereas that of diazinon is $94.82 \%$. This finding was nearly similar with the finding of Dinka et al. [19] who worked at Borana and reported $100 \%$ efficacy of Amitraz and Souza et al. [20], in Southeast Brazil obtained mean Amitraz efficacy of 95\%. The result also in consistent with the report of different authors from different areas at different time reported that the effectiveness of Amitraz over Diazinon [21]. Current study reveals that the sensitivity of Amblyomma variegatum to acaricides was compared based up on the result obtained. Even though, Amblyomma variegatum is sensitive to both acaricides at recommended and double dose, it is relatively more sensitive to Amitraz, but with no great variation on number of tick died due to the application of both drugs. Both compounds seemed to have a comparable and relatively better in-vitro efficacy ( $>90 \%$ at recommended dose) against Amblyomma variegatum with Antiparasitic Efficacy 98.52 of Amitraz and 96.67 Diazinon Recommended dose, after 24 hours post exposure. This finding is consistent with the report of similar result indicated by Turkson and Botchey [22] at Ghana, who reported that field strain of Amblyomma variegatum is resistant to organophosphates like Diazinon.

Generally, the species of ticks used in the study were compared based on their susceptibility to the acaricides used. Even though, both Amblyomma variegatum and Rhipicephalus decoloratus were sensitive to both acaricides at different concentration; they were relatively more sensitive to Amitraz than Diazinon The present study illustrated that the superiority of Amitraz over Diazinon in each concentration against both Amblyomma variegatum and $R$. decoloratus. The result also revealed that Rhipicephalus was relatively resistant to both acaricides than amblyomma. This resistance might be due to regular use of limited acaricide in the area since there is high infestation of ticks. The observation of the result was after 24 hours, which could be resulted by making rhipicephalus was seemed resistant to the drug.

\section{Conclusion and Recommendations}

The present research work demonstrated that amitraz has relatively conserved its tickicidal efficacy in vitro, on both tested tick species than diazinon. A clue of tick insusceptibility to diazinon was noted suggesting a need to consider correct application and choice of acaricides in order to avoid any resistance against ticks. The differences in the efficacy of the two evaluated acaricides (Amitraz and Diazinon) were most likely attributed from one of widespread, frequency, irregular application, inadequate spraying, and improper mixing of acaricides and on the use of acaricides stored for a long time after dilution.

Therefore, the following some basic management were forwarded as the recommendation to reduce the chances of developing acaricides resistance:

- Avoidance of uncontrolled utilization of commercial insecticides and dependence on limited type of acaricides and appropriate and good application of acaricides as prescribed by manufacturer.

- Use of appropriate dose of acaricides during treatment.

- Strategies involving the early detection of resistance and the use of integrated tick control are recommended.

\section{Acknowledgements}

The research was funded by Wollega University Research Ethiopia to which we are grateful. We would like to express our thanks to Bako Woreda Agricultural research center for their assistance during data collection. The research team is also grateful to study participants for their collaboration, enthusiasm and willingness to share us information.

\section{Competing Interest}

We declare that we have no any personal interest that inappropriately influences writing this article.

\section{References}

1. Zenebe S (2005) Ethiopian veterinary association (EVA). Addis Ababa Ethiopia.

2. Taylor MA (2001) Recent developments in ectoparasiticides. The Vet J 161 : 253-268.

3. Koney M (2004) Livestock production and health in Ghana. 2nd edn. Advent Press, Accra, pp: 4-21.

4. Gomes A (1998) O carrapato-do-boi Boophilus microplus: ciclo, biologia, epidemiologia, patogenia e controle. In: Carrapato, tristeza parasitária e tripanossomose dos bovinos. Kessler RH, Schenk MAM (eds.). Embrapa Gado de Corte.

5. Brito LG, Barbieri FS, Rocha RB, Oliveira M, Ribeiro ES (2011) Evaluation of the efficacy of acaricides used to control the cattle tick, Rhipicephalus microplus, in dairy herds raised in the Brazilian southwestern amazon. Vet Med Int 2011: 806093.

6. Yilma J, Adamu G, Zerbini E (2001) Biossay of acaricide resistance on three common cattle tick species at Holotta, Central Ethiopia. Rev Med Vet 152: $385-$ 390.

7. Li AY, Chen AC, Miller RJ, Davey RB, George JE (2007) Acaricide resistance and synergism between permethrin and amitraz against susceptible and resistant strains of Boophilus microplus (Acari: Ixodidae). Pest Manag Sci 63 882-889.

8. Kaljouw M (2009) Resistance to acaricides of Boophilus ticks from cattle in Ghana. MSc Thesis. Veterinary Medicine, Utrecht University, Netherlands.

9. Bako Agricultural Research Center (2014) Weather and climate desks. Bako, Ethiopia.

10. Bako Tibe Woreda Office of Agriculture and Rural Development (BTWOARD) (2015/16) Animal population information desks.

11. Kaiser N (1987) Tick survey, Ethiopia. Report on tick taxonomy and biology. Consultant report. Food and Agricultural Organization of the United Nations, p: 92.

12. Holdsworth PA, Kemp D, Green P, Peter RJ, De Bruin C, et al. (2006) World Association for the Advancement of Veterinary Parasitology (WAAVP) guidelines for evaluating the efficacy of acaricides against ticks (Ixodidae) on ruminants. Vet Parasitol 136: 29-43.

13. Wang GX, Han J, Feng TT, Li FY, Zhu B (2009) Bioassay-guided isolation 
Citation: Tesfaye T, Mohammed C, Yimer L, Duguma M, Mokonnen M (2016) Evaluation of Amitraz and Diazinon against Rhipicephalus decoloratus and Amblyomma variegatum in Bako Agricultural Research Center. J Vet Sci Technol 7: 389. doi: 10.4172/2157-7579.1000389

Page 5 of 5

and identification of active compounds from Fructus Arctii against Dactylogyrus intermedius (Monogenea) in goldfish (Carassius auratus). Parasitol Res 106: 247-255

14. Eshetu E, Dinede G, Lakew M, Tolosa T (2013) In-vitro efficacy evaluation of amitraz $0.025 \%$ and diazinon $0.06 \%$ against Rhipicephalus pulchellus and Amblyomma gemma in Borena pastoral area, Southern rangeland of Ethiopia. J Parasitol Vector Biol 5: 72-76.

15. Furlong J, Martins JR, Prata MCA (2007) The tick of cattle and resistance: we have to celebrate? A Hora Vet 27: 1-7.

16. Santana VLA (2000) Situation of chemical control of Boophilus microplus the sub-regions in the area of forest and wasteland in the state of Pernambuco, based on in vitro efficacy of acaricides in engorged females (Doctora dissertation, Dissertation in Veterinary Science, Federal Rural University of Pernambuco, Recife, Pernambuco, Brazil).

17. Campos Júnior DA, Oliveira PRD (2005) In vitro valuation of acaricides efficiency to Boophilus microplus (Canestrini, 1887) (Acari: Ixodidae) from bovines at the region of Ilhéus, Bahia, Brazil. Ciênc Rural 35: 1386-1392.

18. Camillo G, Vogel FF, Sangioni LA, Cadore GC, Ferrari R (2009) In vitro evaluation of acaricides efficiency to bovine's ticks of Rio Grande do Sul State, Brazil. Ciênc Rural 39: 490-495.

19. Ayana D, Eshetu E, Waketole H, Abunna F (2013) In vitro Acaricidal efficacy evaluation trial of Ixodid ticks at Borana, Ethiopia. Ethiopian Vet J 17: 85-99.

20. de Souza AP, Sartor AA, Bellato V, Perussolo S (2003) Efficacy of acaricides in dairy cattle herds in southern region of Parana state, Brazil. Revista de Ciências Agroveterinárias (Journal of Agroveterinary Sciences) 2: 131-135.

21. Mekonnen S, Bryson NR, Fourie LJ, Peter RJ (2002) Acaricide resistance profiles of single-and multi-host ticks from communal and commercial farming areas in the Eastern Cape and North-West Provinces of South Africa. The Onderstepoort J Vet Res 69: 99-105.

22. Turkson PK, Botchey M (1999) Acaricide resistance in the cattle tick Amblyomma variegatum, in the coastal savanna zone of Ghana. Ghana J Agric Sci 32: 199-204 